Jurnal Manajemen dan Bisnis, Volume 3, No. 1, Juli 2021

\title{
THE INFLUENCE OF MOTIVATION AND WORK ENVIRONMENT ON EMPLOYEE PERFORMANCE IN PLAZA TOYOTA, GREEN GARDEN BRANCH
}

\author{
Helmi $^{1}$, Richardus Risky Ratrigis ${ }^{2}$, Nurwati ${ }^{3}$ \\ Institut Teknologi dan Bisnis Ahmad Dahlan
}

\begin{abstract}
The purpose of this study was to determine the effect of providing motivation and work environment on employee performance at Plaza Toyota Green Garden Branch, in accordance with the indicators set forth in the theory. The values tested in this thesis use the Quantitative Associative testing formula. The results of the validity test of Motivating Variables $\left(X_{1}\right)$ get the results with the number 0.425 , then the $r_{\text {count }} 0.425>r_{\text {table }} 0.279$ is declared valid and the Work Environment variable $\left(X_{2}\right)$ gets the result with the number 0.404 which means valid because the $r_{\text {count }}$ is 0.404> $r_{\text {table }}$ 0.279. Followed by multiple linear regression tests that produce constants of 1,775 which means there is a positive significance of providing motivation and work environment on employee performance with the equation $Y=1.775+0.462\left(X_{1}\right)+0.448\left(X_{2}\right)$. From the results of the coefficient of determination test conducted, obtained $K D=0.333$ or $33.3 \%$ means that $33.3 \%$ employee performance is influenced by providing motivation $\left(X_{1}\right)$ and work environment $\left(X_{2}\right)$, the remaining $66.7 \%$ is influenced by other variables that are not included in this study. Besides that, from the $F$ test results, an $F$ value of 3.20 was obtained using the $F$ distribution table and a significance level of 0.005 , then a $F_{\text {table }}$ of 3.20 was obtained. So it can be seen that $F_{\text {count }}>$ i.e. 11,715> 3.20. Means that $\mathrm{Ho}$ is rejected and Ha is accepted, so that there is a significant influence between the Provision of Motivation and the Work Environment on employee performance at Plaza Toyota Green Garden Branch.
\end{abstract}

Keywords: Motivation, Work Environment, Employee Performance.

\section{PENGARUH MOTIVASI DAN LINGKUNGAN KERJA TERHADAP KINERJA KARYAWAN PADA PLAZA TOYOTA CABANG GREEN GARDEN}

\begin{abstract}
ABSTRAK
Tujuan penelitian ini adalah untuk mengetahui pengaruh pemberian motivasi dan lingkungan kerja terhadap kinerja karyawan pada Plaza Toyota Cabang Green Garden, sesuai dengan indikator yang telah tertuang didalam teori tersebut. Nilai-nilai yang diuji dalam skripsi ini menggunakan formula pengujian Asosiatif Kuantitatif. Hasil uji validitas variabel Pemberian Motivasi $\left(X_{1}\right)$ mendapatkan hasil dengan angka 0,425, maka $r_{\text {hitung }} 0,425>r_{\text {tabel }} 0.279$ dinyatakan valid dan variabel Lingkungan $\mathrm{Kerja}\left(\mathrm{X}_{2}\right)$ mendapatkan hasil dengan angka 0,404 yang berarti valid karena $r_{\text {hitung }} 0,404>r_{\text {tabel }} 0,279$. Dilanjutkan dengan uji regresi linear berganda yang menghasilkan angka constanta 1.775 yang berarti terdapat signifikansi yang posetif dari pemberian motivasi dan lingkungan kerja terhadap kinerja karyawan dengan persamaan $\mathrm{Y}=1.775+0,462\left(\mathrm{X}_{1}\right)+0,482\left(\mathrm{X}_{2}\right)$. Dari hasil uji koefisien determinasi yang dilakukan, diperoleh $\mathrm{KD}=0,333$ atau 33,3\% artinya kinerja karyawan 33,3\% yang dipengaruhi oleh pemberian motivasi $\left(\mathrm{X}_{1}\right)$ dan lingkungan kerja $\left(\mathrm{X}_{2}\right)$, sisanya $66,7 \%$ dipengaruhi oleh variabel lain yang tidak termasuk dalam penelitian ini. Selain itu dari hasil uji $\mathrm{F}$, diperoleh nilai $\mathrm{F}$ sebesar 3,20 dengan menggunakan tabel distribusi $\mathrm{F}$ dan taraf signifikan 0,005, maka diperoleh $F_{\text {tabel }}$ sebesar 3,20. Sehingga dapat diketahui bahwa $F_{\text {hitung }}>$ yaitu 11,715 > 3.20. Berarti Ho ditolak dan Ha diterima, sehingga terdapat pengaruh yang signifikan antara Pemberian Motivasi dan Lingkungan Kerja terhadap kinerja karyawan pada Plaza Toyota Cabang Green Garden.
\end{abstract}

Kata-kata Kunci: Pemberian Motivasi, Lingkungan Kerja, Kinerja Karyawan.

Korespondensi: Helmi, S.Kom., MM. Institut Teknologi dan Bisnis Ahmad Dahlan Jakarta. JL. Ciputat Raya No.77 Cireundeu, Jakarta Selatan 15419. watisyam77@gmail.com 
Jurnal Manajemen dan Bisnis, Volume 3, No. 1, Juli 2021

\section{PENDAHULUAN}

Saat ini semua perusahaan dituntut untuk dapat mengoptimalkan sumber daya manusia dan bagaimana sumber daya manusia itu dikelola. Pengelolaan sumber daya manusia tidak terlepas dari faktor karyawan yang diharapkan dapat berprestasi sebaik mungkin demi mencapai tujuan perusahaan. Sumber daya manusia (SDM) merupakan salah satu faktor yang terpenting dalam sebuah organisasi. SDM perlu dikelolasebaik mungkin untuk mencapai tujuan organisasi. Hal ini sejalan dengan yang dijelaskan oleh Mangkunegara (2015:2) bahwa manajemen sumber daya manusia merupakan suatu perencanaan, pengorganisasian, pengkoordinasian, pelaksanaan, dan pengawasan terhadap pengadaan, pengembangan, pemberian balas jasa, pengintegrasian, pemeliharaan, dan pemisahan tenaga kerja dalam rangka mencapai tujuan organisasi.

Namun dalam upaya mencapai tujuan perusahaan, ada beberapa kendala yang dialami atau dirasakan oleh karyawan. Demi tercapainya tujuan tersebut, maka karyawan memerlukan motivasi untuk bekerja lebih baik dan rajin. Motivasi merupakan dorongan, keinginan, hasrat, kesediaan dan tenaga penggerak yang berasal dari diri manusia untuk berbuat atau untuk melakukan suatu dalam upaya mencapai tujuan perusahaan dan untuk memenuhi kebutuhannya secara individual. Ketika seorang karyawan mempunyai motivasi yang bagus akan berdampak pada kinerjanya, sehingga bisa memberikan kontribusi yang bagus untuk perusahaan.

Selain faktor motivasi kerja, lingkungan kerja tempat karyawan tersebut bekerja juga tidak kalah pentingnya di dalam meningkatkan kinerja karyawan. Dimana Lingkungan Kerja adalah kondisi-kondisi material dan psikologis yang ada dalam perusahaan, dimana yang dimaksudkan adalah bagaimana lingkungan sekitar karyawan dapat menjadi pendukung untuk karyawan mampu menyelesaikan pekerjaan dengan nyaman. Lingkungan kerja yang baik dapat mendukung pelaksanaan kerja sehingga karyawan memiliki semangat bekerja dan meningkatkan kinerja karyawan. Oleh karena itu untuk meningkatkan kinerja, perlu diperhatikan agar sumber daya manusia dapat bekerja secara efisien dan menampilkan kinerja yang bisa memberi sumbangan terhadap produktivitas merupakan masalah mendasar dari berbagai konsep manajemen dan kepemimpinan. Kinerja mengacu pada prestasi kerja karyawan diukur berdasarkan standard atau kriteria yang telah ditetapkan perusahaan. Pengelolaan untuk mencapai kinerja karyawan yang sangat tinggi terutama untuk meningkatkan kinerja perusahaan secara keseluruhan.

Plaza Toyota Green Cabang Garden adalah sebuah perusahaan yang bergerak di bidang penjualan dan perawatan yang termasuk penjualan sparepart dan service untuk segala tipe mobil brand Toyota. Namun demikian, 
Jurnal Manajemen dan Bisnis, Volume 3, No. 1, Juli 2021

dalam upaya menciptakan kinerja karyawan Plaza Toyota Green Cabang Garden, masih terdapat banyak kendala yang dihadapi sehingga sulit untuk mencapai tujuan perusahaan. Kondisi yang belum ideal masih ada di Plaza Toyota Green Cabang Garden, dimana masih ada kendala lain di perusahaan antara lain karyawan yang belum sepenuhnya menaruh antusiasme kepada perusahaan, komitmen yang lemah serta merasa belum terpuaskan dengan apa yang diberikan perusahaan kepada karyawan dan akhirnya berujung pada turnover atau berhentinya seorang karyawan dari perusahaan. Yang juga berdampak pada sikap karyawan yang terlambat masuk bekerja, istirahat lebih awal yang disebabkan oleh motivasi yang rendah. Selain itu kurangnya sarana dan prasarana dalam hal ini lingkungan disekitar area kerja juga sangat berpengaruh seperti peraturan saat bekerja, keamaan, kebisingan, penerangan, sirkulasi udara yang baik bahkan sampai kepada hubungan antar karyawan itu sendiri sehingga mengakibatkan kinerja karyawan menurun dan pekerjaan karyawan tidak dapat terselesaikan sesuai dengan yang direncanakan. Tujuan penelitian :

1. Untuk menganalisis pengaruh motivasi terhadap kinerja

karyawan Plaza Toyota Green Cabang Garden.

2. Untuk menganalisis pengaruh lingkungan kerja terhadap kinerja karyawan Plaza Toyota Green Cabang Garden.

3. Untuk menganalisis pengaruh motivasi dan lingkungan kerja terhadap kinerja karyawan Plaza Toyota Green Cabang Garden.

\section{KAJIAN LITERATUR}

Manajemen adalah ilmu dan seni dalam mengatur pemanfaatan sumber daya perusahaan secara efektif dan efisien untuk mencapai tujuan tertentu. Salah satu unsur manajemen terpenting dalam perusahaan adalah manusia. Manajemen yang mengelola unsur manusia kemudian berkembang menjadi manajemen sumber daya manusia atau kemudian disingkat MSDM. Menurut Mangkunegara (2017:2) bahwa Manajemen sumber daya manusia merupakan suatu perencanaan, pengorganisasian, pengkoordinasian, pelaksanaan, dan pengawasan terhadap pengadaan, pengembangan, pemberian balas jasa, pengintegrasian, pemeliharaan, dan pemisahan tenaga kerja dalam rangka mencapai tujuan organisasi.

Motivasi mempersoalkan daya dan potensi bawahan agar mau bekerja sama secara produktif dalam mencapai dan mewujudkan tujuan yang telah ditentukan. Motivasi ini merupakan hal yang menyebabkan, menyalurkan dan mendukung perilaku manusia supaya mau bekerja giat serta antusias mencapai hasil yang optimal.

Menurut Hasibuan (2014: 99), Motivasi adalah pemberian daya penggerak yang 
Jurnal Manajemen dan Bisnis, Volume 3, No. 1, Juli 2021

menciptakan kegairahan kerja seseorang, agar mereka mau bekerja sama, bekerja efektif dan terintegrasi dengan segala daya upayanya untuk mencapai kepuasan.

Perusahaan bukan hanya mengharapkan karyawan mampu, cakap dan terampil, tetapi juga mau bekerja giat dan berkeinginan untuk mencapai hasil maksimal. Kemampuan dan kecakapan karyawan tidak ada artinya bagi perusahaan jika karyawan tidak mampu bekerja dengan giat dalam mencapai tujuan yang telah ditentukan. Oleh karena itu perusahaan selalu mengharapkan karyawan memiliki motivasi kerja yang tinggi dan perusahaan dituntut mampu memberikan motivasi yang tepat bagi karyawan.

Lingkungan kerja merupakan bagian komponen yang sangat penting ketika karyawan melakukan aktivitas bekerja. Memperhatikan lingkungan kerja yang baik atau menciptkan kondisi kerja yang mampu memberikan motivasi untuk bekerja.

Menurut Nitisemito dikutip oleh Sunyoto (2017:38) lingkungan kerja adalah segala sesuatu yang ada di sekitar para pekerja dan yang dapat mempengaruhi dirinya dalam menjalankan tugas-tugas yang dibebankan, misalnya kebersihan, musik, penerangan dan lain-lain.

Sedangkan menurut Sedarmayanti (2017:2) lingkungan kerja adalah seluruh alat perkakas dan bahan yang dihadapi, lingkungan sekitarnya dimana seseorang bekerja, metode kerjanya serta pengaturan kerjanya baik sebagai perseorangan maupun kelompok. Dari kedua pengertian diatas dapat diketahui, Lingkungan kerja adalah segala sesuatu yang menyangkut tentang karyawan di dalam tempat kerja baik fisik dan non fisik yang berpengaruh terhadap pekerjaan.

Kinerja berasal dari kata job performance atau actual performance yang berarti prestasi kerja atau prestasi sesungguhnya yang dicapai seseorang. Kinerja merupakan salah satu hal yang sangat penting didalam kegiatan perusahaan dan merupakan salah satu sasaran dari manajemen agar tercapainya tujuan perusahaan tersebut.

Mangkunegara (2015:67) menyatakan bahwa Kinerja adalah hasil kerja secara kualitas dan kuantitas yang dicapai oleh seorang pegawai dalam melaksanakan tugasnya sesuai dengan tanggung jawab yang diberikan kepadanya.

\section{METODE}

Desain penelitian manajemen sumber daya manusia ini menggunakan metode penelitian Asosiatif Kuantitaif. Objek dalam penelitian ini adalah karyawan Plaza Toyota Green Cabang Garden yang merupakan perusahaan yang melayani unit jual mobil, Sparepart dan service untuk segala tipe mobil brand Toyota di Jalan Panjang No. 25, Kedoya Utara RT.12/RW.5, Kebon Jeruk, RT.12/RW.5, Kedoya Utara, RT.12/RW.5, Kedoya Utara, Kec. Kb. Jeruk, Kota Jakarta Barat, Daerah Khusus Ibukota Jakarta 11520. 
Jurnal Manajemen dan Bisnis, Volume 3, No. 1, Juli 2021

Dalam penelitian ini variabel bebas (Independent variable) yaitu Pemberian Motivasi (X1), Lingkungan Kerja (X2) dan variabel terikat (Dependent Variable) yaitu Kinerja Karyawan (Y).

Teknik sampling dalam penelitian ini menggunakan teknik pengambilan sampling jenuh, karena jumlah karyawan Plaza Toyota Green Cabang Garden sebanyak 50 orang. Peneliti ingin menjadikan semua karyawan sebagai responden. Penggunaan seluruh karyawan sebagai responden disebut juga Sampling jenuh.

\section{HASIL DAN PEMBAHASAN}

Berdasarkan analisa regresi linear berganda dimana $\mathrm{Y}=\mathrm{a}+\mathrm{b} 1 \mathrm{X} 1+\mathrm{b} 2 \mathrm{X} 2$ maka didapatkan hasil $\quad \mathrm{Y}=1.775+0,462(\mathrm{X} 1)+0,482(\mathrm{X} 2)$ persamaan regresi yang telah diperoleh dapat digunakan untuk melihat seberapa pengaruh pemberian motivasi dan lingkungan kerja terhadap kinerja karyawan pada Plaza Toyota Cabang Green Garden.

Hasil dari analisa koefisien korelasi variabel X1 yaitu $r=0,032$ dan variabel $\mathrm{X} 2 \mathrm{r}=0.425$ artinya terdapat pengaruh yang sedang antara pemberian motivasi dan lingkungan kerja terhadap kinerja karyawan pada Plaza Toyota Cabang Green Garden.

Hasil analisis koefisien determinan diperoleh $\mathrm{KD}=3,33 \%$. Hal ini menunjukkan bahwa kontribusi pemberian motivasi (X1) dan lingkungan kerja (X2) berpengaruh terhadap variabel kinerja karyawan (Y) pada Plaza
Toyota Cabang Green Garden sebesar 3,33\%, sedangkan sisanya dipengaruhi oleh faktorfaktor lain yang tidak diteliti dalam penelitian ini.

Untuk mengetahui apakah pemberian motivasi berpengaruh terhadap kinerja karyawan serta untuk melihat hasil analisa ini signifikan atau tidak, maka perlu dilihat thitung sebesar 3,456 sedangkan ttabel sebesar 1,678. Hal ini berarti thitung lebih besar dari ttabel, maka Ha diterima Ho ditolak. Dengan demikian dapat dinyatakan bahwa terdapat pengaruh yang kuat atau signifikan antara pemberian motivasi terhadap kinerja karyawan. Sedangkan untuk mengetahui apakah lingkungan kerja berpengaruh terhadap kinerja karyawan serta untuk melihat hasil analisa ini signifikan atau tidak, maka perlu dilihat thitung sebesar 3,276 sedangkan ttabel sebesar 1,678. Hal ini berarti thitung lebih besar dari ttabel, maka Ha diterima Ho ditolak. Dengan demikian dapat dinyatakan bahwa terdapat pengaruh kuat atau signifikan antara lingkungan kerja terhadap kinerja karyawan pada Plaza Toyota Cabang Green Garden. 
Jurnal Manajemen dan Bisnis, Volume 3, No. 1, Juli 2021

Hasil perhitungan uji $F$ untuk mengetahui apakah hasil analisis ini signifikan atau tidak, Fhitung sebesar 11,715 dengan tingkat signifikan 0,000. Hal ini menunjukkan bahwa Fhitung lebih besar dari Ftabel yang sebesar 3,20 maka Ha diterima dan Ho ditolak. Dengan demikian dapat dinyatakan bahwa terdapat pengaruh yang kuat atau signifikan antara pemberian motivasi dan lingkungan kerja terhadap kinerja karyawan pada Plaza Toyota Cabang Green Garden.

\section{PENUTUP}

\section{Kesimpulan}

Setelah melakukan penelitian dan pembahasan selanjutnya peneliti ingin mengemukakan beberapa kesimpulan sebagai berikut:

1. Bentuk pemberian motivasi yang dilakukan oleh Plaza Toyota Cabang Green Garden sebagai berikut:

a. Pemberian motivasi dalam bentuk materi

- Gaji

- Bonus

- Insentif

- Tunjangan Hari Raya

- Premi

b. Pemberian Motivasi dalam bentuk nonmateri

- Promosi jabatan

- Pelatihan

- Kegiatan rekreasi

\section{Lingkungan Kerja}

Dapat disimpulkan bahwa kondisi lingkungan kerja pada Plaza Toyota Cabang Green Garden termasuk lingkungan kerja yang baik dan kondusif. Mengingat bahwa Plaza Toyota cabang Green Garden ini adalah pusat penjualan dan servis mobil Toyota yang artinya bersentuhan langsung dengan pelanggan dan lingkungan kerja namun dapat dikatakan sangat baik dan kondusif.

Saran

1. Berdasarkan hasil kuesioner tentang pemberian motivasi (X1) terdapat nilai tertinggi pada pernyataan Keterlibatan karyawan dalam pengambilan keputusan yang ditetapkan perusahaan akan membuat karyawan temotivasi dalam bekerja dengan jumlah responden yang menyatakan sangat setuju sebanyak 18 orang atau $36 \%$ dan pernyataan Karyawan yang telah diberikan kepercayaan dalam menjalankan tugas sesuai tanggung jawabnya akan memotivasi karyawannya dalam bekerja, dengan jumlah responden yang menyatakan sangat setuju sebanyak 18 orang atau 36\%. Oleh karena itu, sebaiknya pihak manajemen Plaza Toyota Cabang Green Garden untuk terus meningkatkan perubahan kearah yang lebih baik dengan selalu memberikan kesempatan bagi karyawan untuk dapat ikut dalam pengambilan keputusan dan memberikan kepercayaan pada karyawan dalam menjalankan pekerjaannya.

2. Berdasarkan hasil kuesioner tentang Lingkungan Kerja (X2) terdapat nilai tertinggi pada pernyataan Sirkulasi udara di tempat kerja membuat saya bernafas dengan oksigen yang cukup dengan jumlah responden yang menyatakan sangat setuju sebanyak 26 orang atau $52 \%$. Oleh karena itu, sebaiknya pihak 
Jurnal Manajemen dan Bisnis, Volume 3, No. 1, Juli 2021

manajemen Plaza Toyota Cabang Green Garden untuk terus memperhatikan Lingkungan Kerja agar sirkulasi udara yang baik dapat selalu terjaga. Terlepas dari sirkulasi udara yang baik, pihak manajemen juga diharapkan selalu menjaga kenyamanan lingkungan kerja baik dari hubungan antar karyawan hingga yang bersangkutan dengan lingkungan kerja fisik perusahaan.

\section{DAFTAR PUSTAKA}

Edison, Emron, Yohny Anwar dan Imas Komariyah, 2017. Manajemen Sumber Daya Manusia. Bandung. CV. Alfabeta

Hartatik, Indah Puji. 2014. Buku Praktis Mengembangkan SDM. Yokyakarta. Laksana

Hasibuan, Malayu S.P. 2014. Manajemen Sumber Daya Manusia. Jakarta: Bumi. Aksara.

Kasmir, 2018. Manajemen Sumber Daya Manusia (Teori dan Perilaku). Jakarta, Raja Grafindo Persada.

Kusuma, Widya, Aqsa, 2017. Pengaruh Motivasi dan Lingkungan Kerja Terhadap Kinerja Karyawan pada PT. Bank Tabungan Negara (Persero) Tbk Kantor Cabang Syariah Bogor. Sekolah Tinggi Ilmu Ekonomi Ahmad Dahlan Jakarta,

Mangkunegara, A.A Anwar Prabu, 2015. Manajemen Sumber Daya Manusia. Jakarta. CAPS Bumi Aksara

2017. Manajemen Sumber Daya Manusia Perusahaan. Bandung. PT. Remaja Rosda Karya

Purwatiningsih, Anjar. 2017. Pengaruh Morivasi Terhadap Kinerja Karyawan Pada Pusat Badan Pendidikan dan Pelatihan Bahasa dan Badan Pendidikan dan Pelatihan Kementrian Pertahanan Jakarta, Institut Teknologi dan Bisnis Ahmad Dahlan Jakarta.
Sedarmayanti, 2017. Tata Kerja Dan Produktivitas Kerja. Bandung. Mandar Maju

Siregar, Sofyan, Ir, 2015. Metode Penelitian Kuantitatif Dilengkapi Dengan Perbandingan Perhitungan Manual Dan SPSS. Jakarta. Prenada Media Group.

Sunyoto, Danang. 2017. Penelitian Sumber Daya Manusia. Yogyakarta. PT. Buku Seru

Sugiyono, 2017. Metode Penelitian Kuantitatif, Kualitatif dan R\&D. Bandung. Alfabeta $C V$.

Sujarweni, Wiratna, 2014. Metodologi Penelitian. Yogyakarta. PT. Pustaka Baru Press.

Sutrisno, Edy. 2017. Manajemen Sumber Daya Manusia. Jakarta. Kencana Prenada Media Group.

Wibowo, 2017. Perilaku Dalam Organisasi. Depok. PT. Raja Grafindo Persada. , 2017. Manajemen Kinerja. Depok. PT. Rajagrafindo Persada 